\title{
Comparison between the Energy Required for Production of PV Module and the Output Energy Througout the Product Life Time
}

\author{
Léa Beatriz Dai Prá, João Batista Dias and Amanda Gonçalves Kieling \\ Laboratório de Energias Renováveis, UNISINOS (Universidade do Vale do Rio dos Sinos), São Leopoldo 93.022-000, Brazil
}

Received: March 13, 2015 / Accepted: May 04, 2015 / Published: June 30, 2015.

\begin{abstract}
Electrical energy consumption is growing and is necessary to improve the technologies related to energy production. We have carried out a pilot study about environmental impacts during the manufacturing process of PV (photovoltaic) modules and compared between the energy requirement for the production of PV cells and modules and generation throughout the life time of the finished good that is PV module. It was taken into account the generation of environmental aspects and impacts in the manufacture of monocrystalline silicon PV modules (consisting of three components: silicon cell, flat tempered glass and aluminum frame), and an analysis of a grid-connected PV system using an energetic alternative in residences was considered. Results show that, this kind of renewable energy is really clean and can be considered as a way to change the energy technology.
\end{abstract}

Key words: Manufacturing of PV modules, generation of environmental impacts, grid-connected PV system.

\section{Introduction}

With the advances in society in the matter of sustainability, the use of renewable energy is more and more frequent, mainly because they are considered clean energy. The generation of electricity, through PV (photovoltaic) modules, has become increasingly recognized in this area.

In a matter of use, solar PV energy is really clean. However, during the manufacturing of its components, many environmental impacts can be generated. These, in turn, should be studied in order to improve processes, especially as it relates to energy costs, taking into account the energy consumed in the manufacturing of a module and the energy that it produces during its lifetime.

The main objective of this study is to analyze the anufacturing processes of monocrystalline silicon photovoltaic modules, environmental aspects and

Corresponding author: João Batista Dias, Ph.D., research field: photovoltaic systems. E-mail: joaobd@unisinos.br. impacts at each stage of manufacturing as well as the energy generation in a residential grid-connected system during its use.

\section{Review}

Photovoltaic solar energy is obtained by direct conversion of solar radiation into electricity (photovoltaic effect). The PV effect is the appearance of an electrical potential difference in the extremes of a semiconductor material structure, produced by part absorption of the solar radiation spectrum [1].

A PV module is composed of individual cells connected in series, tempered glass with low iron content, on the side that faces the sun and an aluminum frame [2].

Fig. 1 shows a schematic composition of a standard photovoltaic module, of monocrystalline silicon.

According to the type of semiconductor material that forms the solar cells, they are classified into different groups. The most common types of PV modules are manufactured with cells formed of $\mathrm{m}-\mathrm{Si}$ 


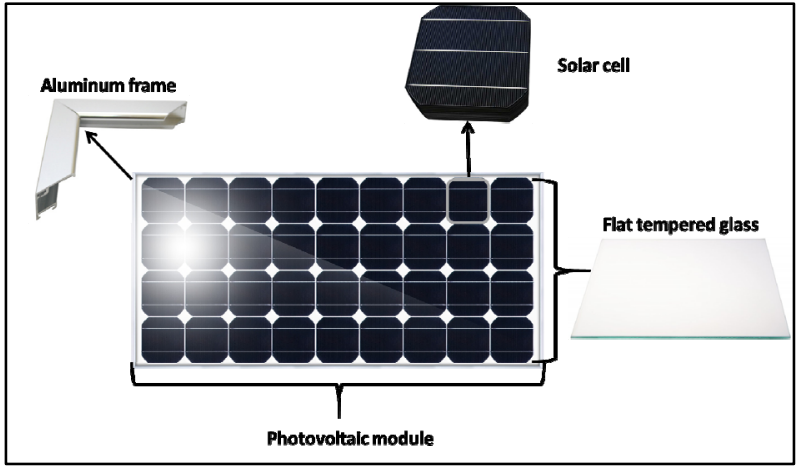

Fig. 1 Components of a standard photovoltaic module.

(monocrystalline silicon) and $\mathrm{c}-\mathrm{Si}$ (polycrystalline silicon) [3].

The efficiency of a PV module composed of $\mathrm{m}-\mathrm{Si}$ cells, in converting solar radiation into electricity, is higher than $12 \%$ [2].

Because they have an efficiency of $12 \%$, the modules with $\mathrm{m}-\mathrm{Si}$ cells are better suited for the production of electricity [4].

The classical method of manufacturing $\mathrm{m}-\mathrm{Si}$ cells uses a method known as $\mathrm{Cz}$ (Czochralski Method), which gets the silicon from the processing of silica [3]. The method consists of introduce a seed crystal in molten silicon, then, slowly lowering the temperature, to give crystallization. After obtaining the monocrystal, it passes by mechanical machining, cutting, thinning, rounding of the edges, cleaning and polishing, obtaining finally the monocrystalline silicon wafers [5].

Energy consumption in this process is extremely intense and complementary steps to the monocrystal growth have considerable material losses, in the order of $50 \%$ of the original billet [6].

In the framework of the PV module, there are two glass functions: to protect the solar cell and provide the transparency necessary for the transmission of solar radiation. In this case, the glass appears to be the most efficient and versatile option. It should be able to withstand bad weather (rain, wind, hail and snow), thermal shock and smaller mechanical impacts [7].

The glass can be classified as flat, hollow or special. Flat glass is produced in the form of plates (which can later be cut and processed). This is the material suitable for use in photovoltaic modules, as it has the characteristics needed for this function [8].

As it needs to be robust, flat glass is tempered. Its production occurs through a horizontal or vertical tempering furnace. After being undergone a rapid heating and cooling process, it starts to have a resistance up to five times higher, compared to its natural state. Once tempered, the glass cannot be benefited, cut or punctured. Therefore, any process of transformation must be done before the tempering process. Tempered glass is resistant to thermal shock, bending, buckling, twisting and weight. When broken, it breaks into small pieces, also reducing the risk of accidents involving cuts [8].

In a study of LA (lifetime analysis), inherent impacts in the glass manufacturing process were identified, particularly in relation to the high temperature required for melting the raw material, which results in a big emission of carbon dioxide and harms human health. [9].

The aluminum is a rigid and conductive material that serves as PV module enclosure structure and for its fixing. The primary aluminum is produced in three stages: extraction of bauxite, obtaining of alumina by the Bayer process and obtaining the aluminum by casting [3].

Although aluminum has a low financial cost, the environmental costs of its mining and refining, can be high. The environmental impact extends from forest degradation and water contamination with their combings, to the direct influence of contamination in ecosystems. It is necessary to extract from 4 tons to 5 tons of bauxite to produce 2 tons of alumina that, in turn, results in the production of one tone of primary aluminum [3].

One of the main attributes of aluminum is that, it can be recycled numerous times, both of used products, such as slag from its casting [10].

The energy requirement for the production of a standard photovoltaic module, of approximately one meter long, half a meter wide and 32 cells, is 


\section{$1,373.72 \mathrm{kWh}[3]$.}

Considering the module power of $74 \mathrm{Wp}$, daily use of $6 \mathrm{~h}$ and an approximate service lifetime of 25 years, it is able to generate $4,051.50 \mathrm{kWh}$ in this period, in other words, $162.06 \mathrm{kWh} /$ year. The time required of the module operating, so it can repay its energy production spending, is 8.48 years. Consequently, 16.52 environmentally useful years of lifetime would remain after the module achieves its energy balance in relation to the energy costs of its production [3].

As the PV system does not emit pollutants during its operation, it is very promising as a sustainable alternative energy. However, it generates environmental impacts to be considered. The most significant environmental impact of photovoltaic system for electricity production is caused during the manufacturing of its materials and construction, and also, related to the area of deployment [11].

\section{Methodology}

The methodology is to analyze the manufacturing processes of the components of mono-crystalline silicon PV modules qualitatively, pointing out the steps of the process and making the survey of environmental aspects and impacts involved, also, to study the energy generation in a residential grid-connected system.

First, a literature review about the components of the PV module and its manufacturing characteristics was performed. From this research, a detailed flowchart of the processes was obtained and, based on the flowchart and the theoretical evaluation, a complete analysis of environmental aspects and impacts, was performed.

\subsection{PV System}

Sample PV system for the consideration the consumption of a house with four people was estimated. The simulation was made in a simulator of the COPEL (Companhia Paranaense de Energia), was obtained a monthly consumption of $166 \mathrm{kWh}$, around $2,000 \mathrm{kWh} /$ year.

Fig. 2 shows a diagram of the system. The system contains a $1,700 \mathrm{~W}$ inverter to grid-connected photovoltaic power systems and twenty $100 \mathrm{Wp}$ modules. The PV arrangement is composed of two parallel branches, each one with ten modules connected in series. The total installed capacity is $2 \mathrm{kWp}$. The system was dimensioned to a residence in the city of Porto Alegre, Brazil.

\section{Results}

Part of the result was obtained from the studied literature and the qualitative analysis of environmental aspects and impacts. This made possible to compile a flow chart of the steps of each process involved in the production of mono-crystalline silicon photovoltaic modules. To construct a table that lists the environmental impacts related to the relevant stages of the process. Rest of the result was obtained from simulation of sample PV generation system. That provided the quantification of the energy consumption in a residence and the produced energy by the PV system, enabling the study between the impacts during manufacturing of a module and its total energy production throughout the life time.

\subsection{Simplified Flowchart of Process Steps}

Different types of lines in Fig. 3 show different types of module components.

\subsection{Environmental Impacts at Each Stage}

Based on the survey of the steps mentioned in flow chart, it was possible to conclude Table 1, mentioned the relevant steps to each process and impacts originated in the module manufacturing as a whole. Each component has a corresponding letter and in the second and third columns, it is possible to identify the relationship of each component in the module manufacturing steps. The environmental aspects and impacts are for all the steps. 


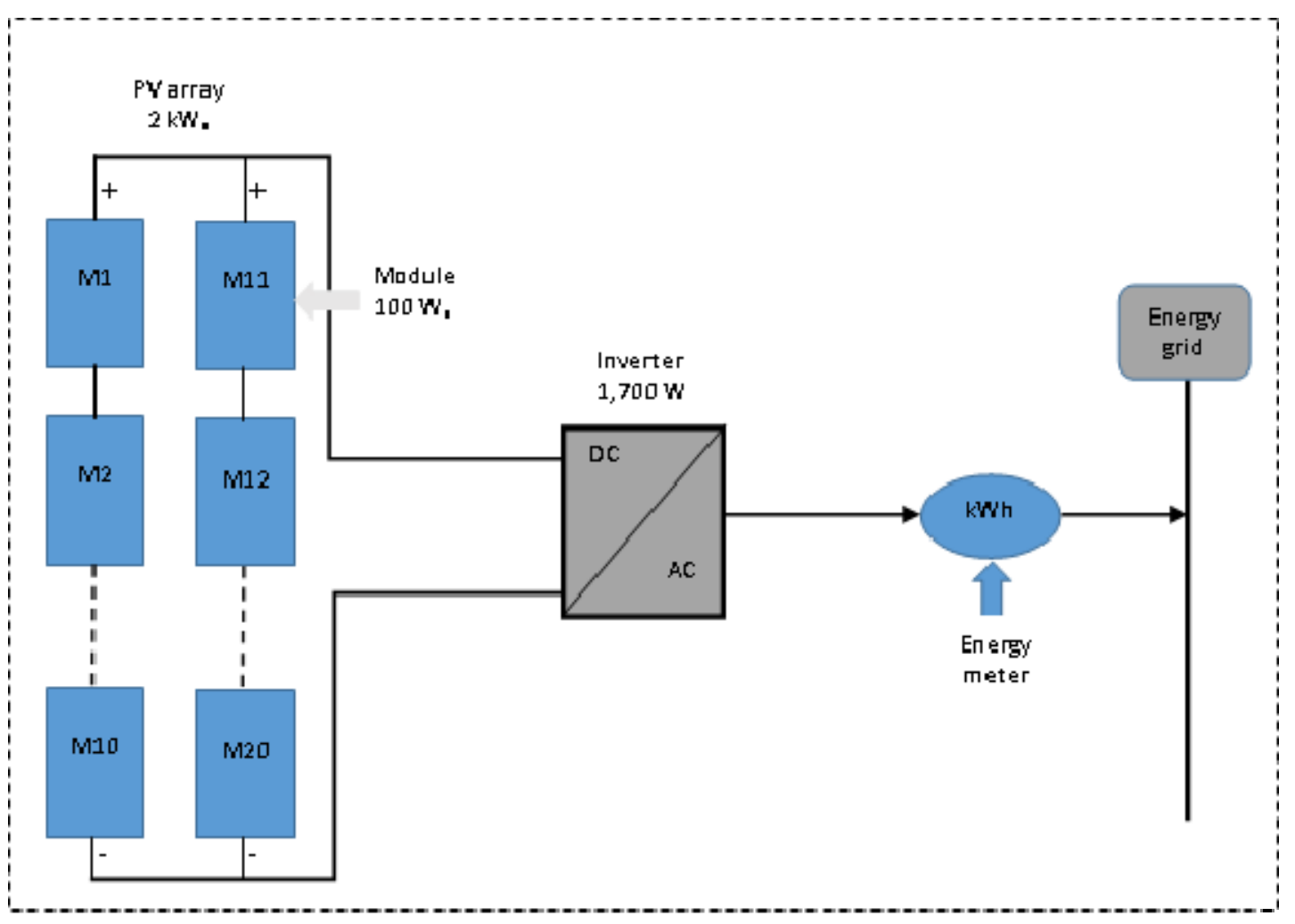

Fig. 2 PV system diagram.

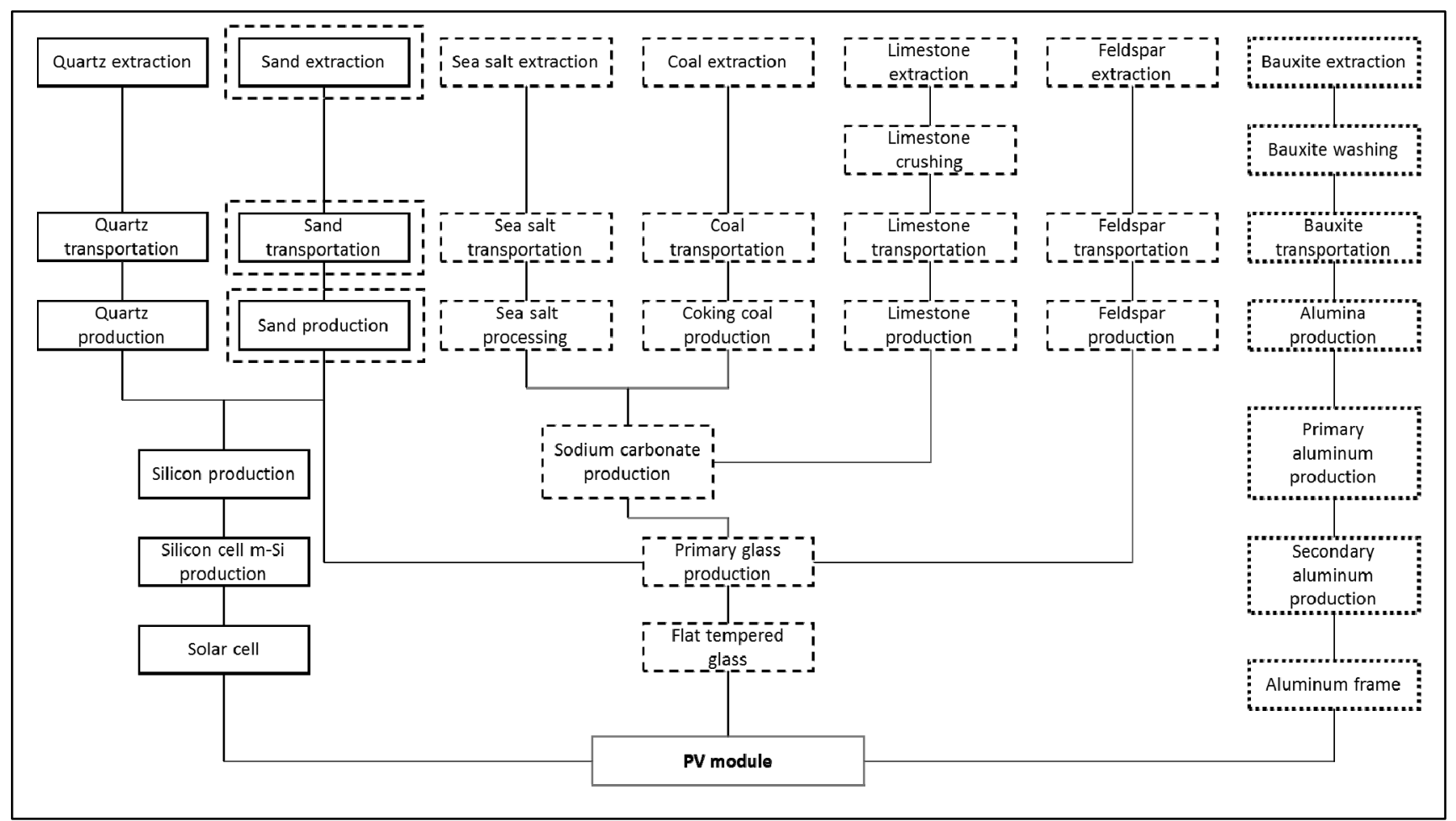

Fig. 3 Flowchart of manufacturing processes of a m-Si PV module. 
Table 1 Generation of environmental aspects and impacts in the manufacture of PV modules.

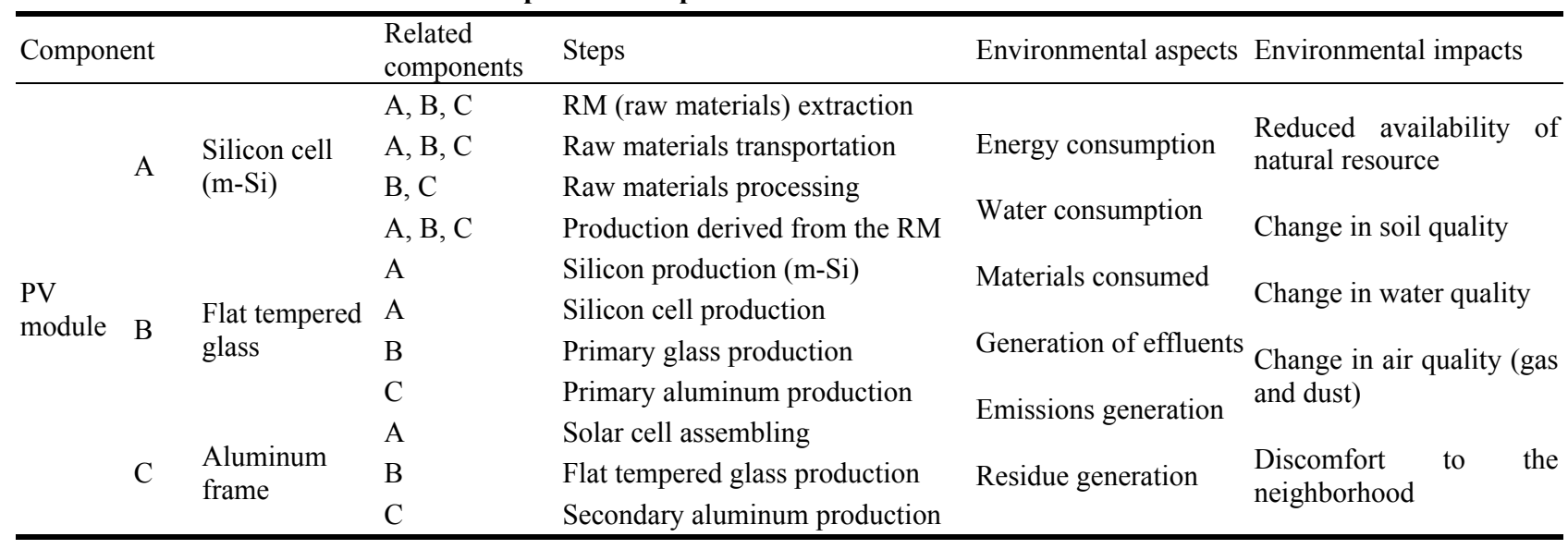

Table 2 Energy consumption.

\begin{tabular}{ll}
\hline Energy consumed by module components & \\
\hline Flat tempered glass & $73.55 \mathrm{kWh}$ \\
Aluminum frame & $146.04 \mathrm{kWh}$ \\
Solar cell & $487.42 \mathrm{kWh}$ \\
\hline
\end{tabular}

Table 3 Simulation results.

\begin{tabular}{ll}
\hline Annual simulation & \\
\hline Energy produced by the PV system & $2,201.50 \mathrm{kWh}$ \\
Energy injected on the grid & $1,469.81 \mathrm{kWh}$ \\
Energy available from the grid & $1,268.31 \mathrm{kWh}$ \\
Own residential consumption & $731.69 \mathrm{kWh}$ \\
Own consumption (\%) & $33.2 \%$ \\
\hline
\end{tabular}

The energy consumed by each component of the module is show in Table 2 .

\subsection{Energy Production}

The PV system dimensioning was performed in the program Sunny Design by SMA Solar Technology AG [12]. It has an angle of $20^{\circ}$, and a annual consumption of 2,000 kWh. Result is shown in Table 3.

\subsection{Energy Consumption x Energy Produced}

Using the literature as a base, the energy consumption costs in the manufacture process of a module are approximately $708 \mathrm{kWh}$. The annual quantity of energy produced by the system of 20 modules, obtained at simulation is $2,201.50 \mathrm{kWh}$. The energy to produce the 20 modules is $14,140.2 \mathrm{kWh}$. Considering a medium lifetime of 25 years, the total generation of the system is approximately $55,040 \mathrm{kWh}$.
Analyzing the data and discounting the energy consumed in the manufacturing, there are still approximately $40,900 \mathrm{kWh}$ to use as completely clean energy. Specifically, the system will take approximately $25 \%$ of its life to compensate for the energy demand, but it will still be self-sustaining for over 18 years.

\section{Conclusions}

The process analysis of manufacture of $\mathrm{m}-\mathrm{Si} \mathrm{PV}$ module components qualifies environmental aspects and impacts. Process analysis is an effective tool for qualitative studies. However, the proposed PV system, simulated for the period of one year, compared the energy costs in the manufacture processes of the components with its use in a standard residence, making possible a quantitative study.

As the results show, if taken into account the energy used in the manufacture of a module (as quantified in literature), and the energy that a module system produces (as simulated), this technology proves to be self-sustainable. Because of having many years of clean energy production, even if in the first year, the system equals the energy spending in manufacturing, with gains in use.

Renewable energies are becoming more frequently, an alternative way of energy generation. The PV energy is one of them. With directed researches in this area and the right support, the manufacturing 


\section{Output Energy Througout the Product Life Time}

processes may be improved and this can reduce even more the environmental impacts, turning it on a complete sustainable way to generate energy.

\section{Acknowledgments}

Thanks to Unisinos (Universidade do Vale do Rio dos Sinos) and FAPERGS (Fundação de Amparo à Pesquisa do Estado do Rio Grande do Sul) for providing the opportunity to accomplish this project.

\section{References}

[1] Guimarães, A. P. C. 2004. Engineering Manual for Photovoltaic Systems. Rio de Janeiro: GTES-Solar Energy Working Group.

[2] Almeida, F. S., and Ferreira, T. S. 2010. "Study on the Production and Use of Solar Panels as a Source of Renewable Energy." Journal of Dissemination of the Project "Petrobras University" and the Federal Fluminense Institute 1: 257-61.

[3] Rosa, C. A. 2008. "Study of the Energy Balance and Environmental Liabilities Resulting from the Manufacture of Photovoltaic Module." In Graduate Program in Energy Engineering, Itajubá: Federal University of Itajubá.

[4] Rosa, C. A., and Tiago Filho, G. L. 2007. Renewable Energy Series: Solar. Itajubá: FAPEPE-Foundation to Support Teaching, Research and Extension of Itajubá.

[5] Mori, V., Santos, R. L. C., and Sobral, L. G. S. 2007. Silicon Metallurgy: Obtaining Processes and
Environmental Impacts. Rio de Janeiro: CETEM-Mineral Technology Center.

[6] Rüther, R. 2004. Photovoltaic Solar Buildings: Potential of the Integrated Photovoltaic Solar Generation to the Urban Buildings and Connected to the Public Grid in Brazil. Florianópolis: UFSC (Federal University of Santa Catarina).

[7] Blue Sol. 2009. The Photovoltaic is Here to Stay: Panels that Transform Solar Energy into Electricity are Gaining Ground Worldwide. São Paulo: The Flat Glass.

[8] Montano, P. F., and Bastos, H. B. 2013. "The Flat Glass Industry: Current Situation and Prospects. BNDES-National Bank for Economic and Social Development." BNDES Sectorial 38: 265-90.

[9] Gadea, M. M. 2010. LCA (Life Cycle Analysis) Application on a Flat Glass Industry. Joinville: Department of Production and Systems Engineering, CCT-Center of Technological Sciences, University of the State of Santa Catarina.

[10] Moura, A. R. S. 2008. Process for Obtaining Aluminum. Belém: Mechanical Engineering Faculty-WEF Technology Institute-ITEC, Federal University of Pará-UFP.

[11] Inatomi, T. H. I., and Udaeta, M. E. M. 2011. Analysis of the Environmental Impacts of Energy Production within the Integrated Resource Planning. São Paulo: USP-São Paulo University.

[12] SMA Solar Technology AG. 2012. Sunny Design 2.11 Software. SMA Solar Technology Company. Accessed April 14, 2013. http://www.sma-france.com /fr/produits/logiciels/sunny-design.html. 